\title{
CORRELATION OF SWITCHING OVERVOLTAGES OVER TRANSPOSED AND UNTRANSPOSED TRANSMISSION LINES
}

\author{
M. HAMED and D. ISMAIL \\ Electrical Power Dept., Faculty of Engineering, Suez Canal University, Port Said, \\ Egypt \\ (Received July 30, 1986)
}

This paper presents a computational analysis of the difference between the values of the self parameters (resistance, inductance and potential coefficient) of some typical transmission lines. The earth return effect is included. A new coefficient of unsymmetry for the untransposed transmission line parameters is proposed. The wave mode parameters as a function of the given coefficient of unsymmetry are deduced.

The balancing of the parameters of both transposed and untransposed lines is applied. The percentage error in the calculated voltage at any point of the untransposed line, if considered as transposed, is formulated.

\section{INTRODUCTION}

The study of electromagnetic transients is essential for the adequate design and operation of power systems. The main difficulties confronting the power system analyst in studies of untransposed transmission lines are the establishment of models which are sufficiently general to represent the power system components in an adequate manner for any frequency ${ }^{1}$.

Models which assume constant parameters do not adequately simulate the response of the actual line during transient conditions and produce a magnification of the higher harmonics and wave distortion. Much effort has been devoted over the last several years to the development of frequency-dependent line models for digital computer transient simulations ${ }^{2}$.

Experimental studies of induced overvoltages on distribution lines are comparatively rare, and few measurements have been obtained in the absence of complicating factors such as surge arresters, transformers and terminal equipments ${ }^{3}$. 


\section{PROBLEM FORMULATION}

In estimating the switching overvoltages that may be developed in various elements of an electric network, extensive use of the most successful method for computation using the traveling wave technique was made ${ }^{4}$.

A proper modelling for the calculations of transients in transposed and untrasposed lines with frequency dependent parameters is required so that the method in ${ }^{5}$ is chosen. This important technique is based on the modal analysis which decouples the line phases ${ }^{6}$.

It has been reported that these simplified methods lead to good results only in the case of line energization, but are less accurate for fault clearing and single phase reclosure due to the unsymmetry ${ }^{7}$. Also, in the case of energization, the unsymmetry characteristics lead to an error in the calculated values of voltage so that this error should be evaluated. This problem appears more important with the EHV and UHV long distance transmission lines.

\section{THE MATHEMATICAL ANALYSIS}

The matrix of line parameters [Z] such as inductance, resistance and potential coefficient in phase coordinates can be expressed $a^{8}$ :

$[\mathrm{Z}]=\left[\begin{array}{lll}\mathrm{Z}_{\mathrm{aa}} & \mathrm{Z}_{\mathrm{ab}} & \mathrm{Z}_{\mathrm{ac}} \\ \mathrm{Z}_{\mathrm{ab}} & \mathrm{Z}_{\mathrm{bb}} & \mathrm{Z}_{\mathrm{bc}} \\ \mathrm{Z}_{\mathrm{ac}} & \mathrm{Z}_{\mathrm{bc}} & \mathrm{Z}_{\mathrm{cc}}\end{array}\right]$

The self parameters $\mathrm{Z}_{\mathrm{aa}}, \mathrm{Z}_{\mathrm{bb}}$ and $\mathrm{Z}_{\mathrm{cc}}$ including the earth return effect $^{9}$ for different typical transmission lines 220 and $330 \mathrm{kV}$ which are shown in Fig. 1 are determined. The calculated maximum percentage differences between the maximum and minimum self parameters $\mathrm{Z}_{\mathrm{aa}}$ and $\mathrm{Z}_{\mathrm{cc}}$ for the resistance and inductance of these lines are shown in Fig. 2.

It is shown that this percentage difference between the parameters is frequency dependent. The evaluated maximum percentage difference for line potential coefficient is listed in Table I. 


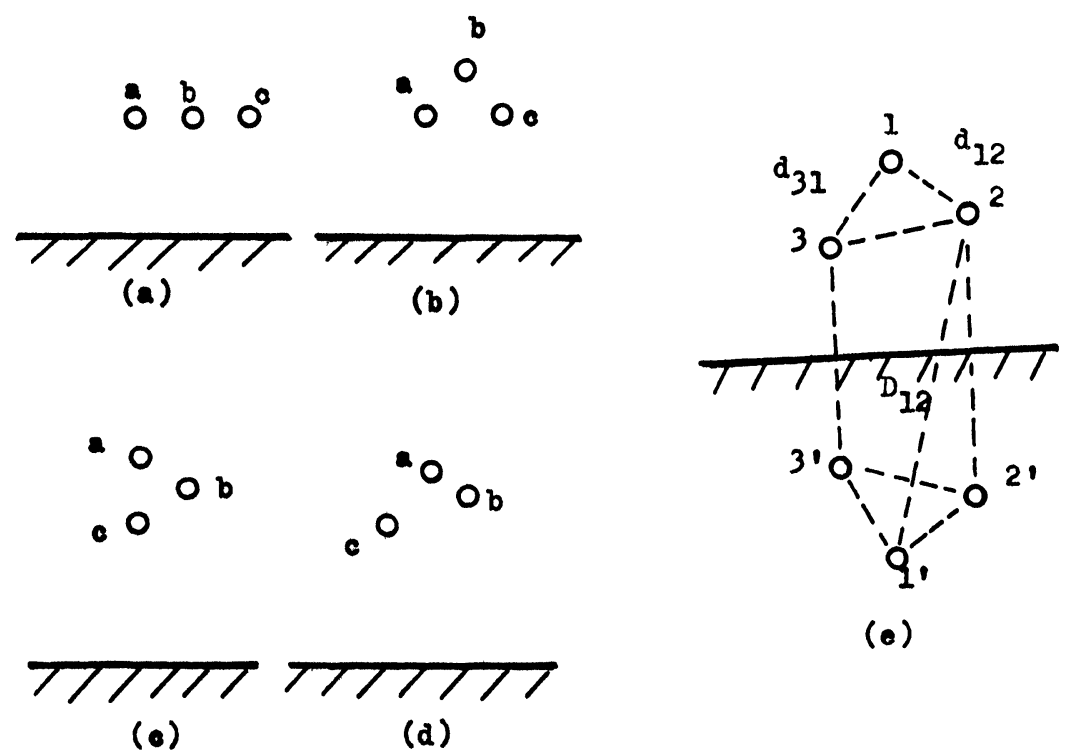

FIGURE 1 The arrangement of phases of typical transmission lines. (a) $750 \mathrm{kV}$,

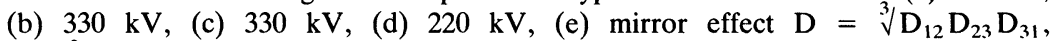
$d=\sqrt[3]{d_{12}} d_{23} d_{31}$.

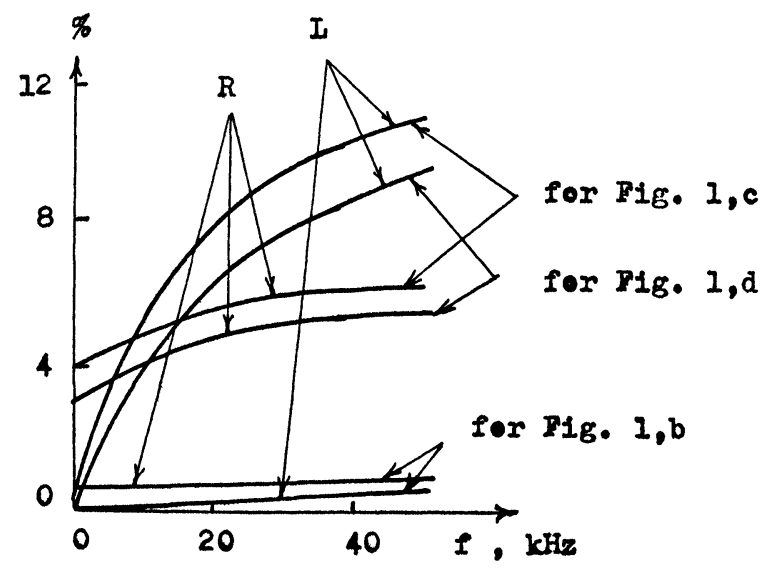

FIGURE 2 The calculated percentage difference between the parameters of the typical transmission lines. 
TABLE I

\begin{tabular}{|c|c|c|c|c|}
\hline Geometry of phases & $\begin{array}{lll}a & b & c \\
o & \circ & o\end{array}$ & ${ }_{0}^{a}{ }^{\circ} b_{0}$ & ${ }_{\text {Oc }}^{\mathrm{aO}} \mathrm{Ob}$ & $\mathrm{o}_{\mathrm{c}}^{\mathrm{a} O} \mathrm{Ob}$ \\
\hline Voltage class $(\mathrm{kV})$ & 750 & 330 & 330 & 220 \\
\hline Max. difference (\%) & zero & 1.5 & 8.8 & 8.5 \\
\hline
\end{tabular}

Refering to the middle phase, the computed maximum percentage difference for the line paramaters will be decreased to its half value. In this case, the limit of maximum difference for all parameters (Fig. 2) in the frequency region $(0-50 \mathrm{kHz})$ becomes $5.5 \%$. Thus, the scale for the curves that given in Fig. 2 may be halfed, except for the curves 1 and 2 where their scale should be unchanged.

\section{COEFFICIENT OF UNSYMMETRY}

The unsymmetry of three phase transmission line may be measured by the ratio of two mutual parameters. Thus, two coefficients of unsymmetry $K_{1}$ and $K_{2}$ will be defined as the ratio of each of two mutual parameters of the line. These coefficients can be written as:

$\mathrm{K}_{1}=\frac{\mathrm{Z}_{\mathrm{ab}}}{\mathrm{Z}_{\mathrm{ac}}} \quad$ and $\quad \mathrm{K}_{2}=\frac{\mathrm{Z}_{\mathrm{bc}}}{\mathrm{Z}_{\mathrm{ac}}}$

By inserting equation (2) with two unity coefficients of unsymmetry $\left(\mathrm{K}_{1}=\mathrm{K}_{2}=1\right)$, the matrix (1) will represent the case of completely transposed transmission line. Taking only two equal coefficients of unsymmetry $\left(\mathrm{K}_{1}=\mathrm{K}_{2}\right)$, the matrix (1) becomes suitable for the transmission line arrangement of Fig. 1a.

The relation between the two coefficients of unsymmetry $K_{1}$ and $\mathrm{K}_{2}$ must be studied. These coefficients for inductance, resistance and potential coefficient of typical transmission lines (Fig. 1) are obtained and shown in Fig. 3. Both $\mathrm{K}_{1}$ and $\mathrm{K}_{2}$ are a function of frequency. For resistance practically the two coefficients are nearly equal, while for inductance the difference between them has its maximum at $50 \mathrm{kHz}$.

Since the capacitance of the line is taken as constant ${ }^{5}$, the cal- 


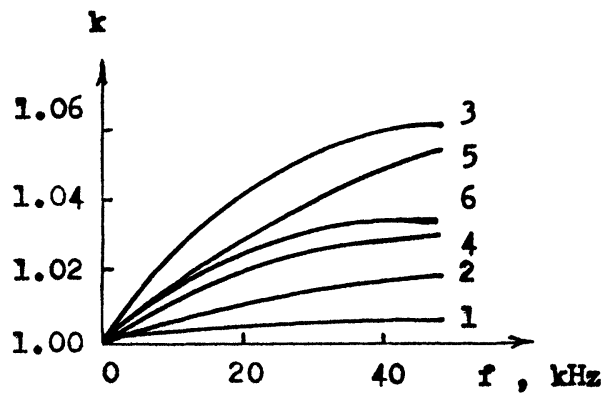

(a) for resistance

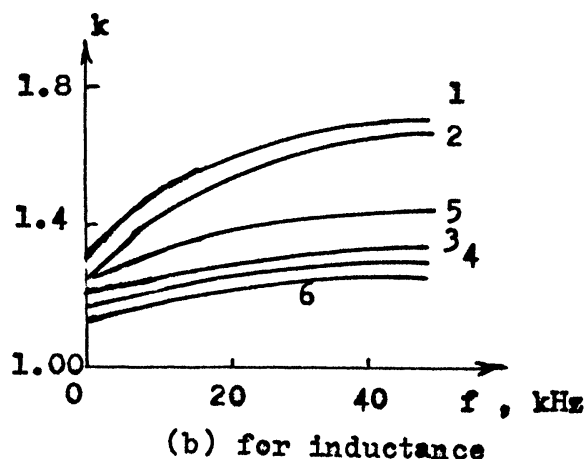

FIGURE 3 The frequency characteristics of coefficient of unsymmetry.

curve $1 \ldots$ for Fig. 1(b)

curve 2 ... for Fig. 1(a)

curves 3 and 4 ... for Fig. 1(c)

curves 5 and $6 \ldots$ for Fig. 1(d)

culated coefficients of unsymmetry for the potential coefficients are frequency independent as listed in Table II.

Calculations prove that the two coefficients are sufficiently close each to another so only one coefficient of unsymmetry $\mathrm{K}$ can be considered.

The wave mode parameters $\mathrm{Q}_{\alpha, \beta, \mathrm{o}}$ in wave mode coordinates $(\alpha, \beta, o)$ for the transmission line phase parameters [Z] will be a function of the proposed coefficient of unsymmetry $\mathrm{K}$ as shown in Fig. 4, and their values may be evaluated by ${ }^{10}$ : 
TABLE II

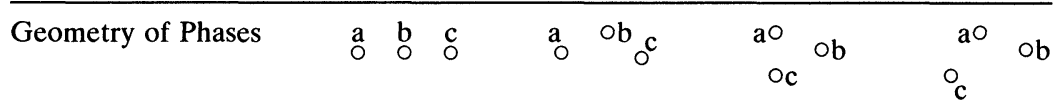

\begin{tabular}{lrrrr}
\hline Voltage class $(\mathrm{kV})$ & 750 & 330 & 330 & 220 \\
\hline $\mathrm{K}_{1}$ & 1 & 1 & 1.47 & 1.63 \\
\hline $\mathrm{K}_{2}$ & 1 & 1 & 1.42 & 1.52 \\
\hline
\end{tabular}

$\mathrm{Q}_{\alpha, \beta, \mathrm{o}}=\mathrm{Y}_{\alpha, \beta, \mathrm{o}}+\mathrm{Z}_{\mathrm{bb}}$

where $\mathrm{y}_{\alpha, \beta, \mathrm{o}}$ is the wave mode term, as shown in Fig. 4, from which the wave mode parameters $\mathrm{Q}_{\alpha, \beta, \mathrm{o}}$ can be formulated as:

$$
\begin{aligned}
& \mathrm{Q}_{\alpha}=\mathrm{Z}_{\mathrm{bb}}+\mathrm{Z}_{\mathrm{ac}}(1.198-0.198 \mathrm{~K}) \\
& \mathrm{Q}_{\beta}=\mathrm{Z}_{\mathrm{bb}}+\mathrm{Z}_{\mathrm{ac}}(1.01-0.01 \mathrm{~K}) \\
& \mathrm{Q}_{\mathrm{o}}=\mathrm{Z}_{\mathrm{bb}}+\mathrm{Z}_{\mathrm{ac}}(0.66+1.34 \mathrm{~K})
\end{aligned}
$$

Equations (4) are satisfactory for both transposed and untransposed transmission lines. Thus, the parameters of the $\beta$-wave mode

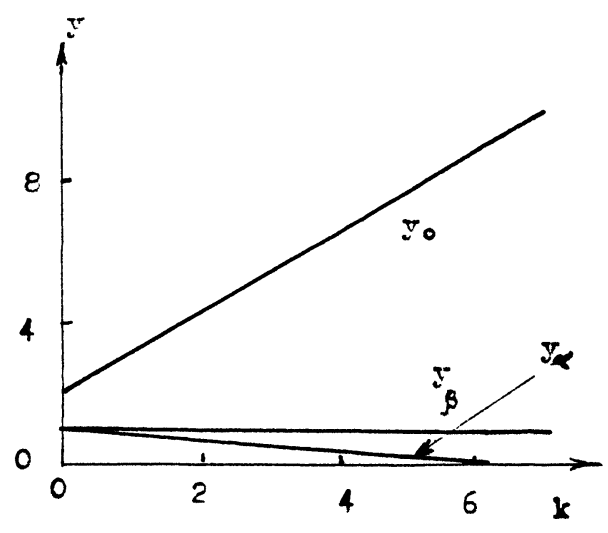

FIGURE 4 The wave mode terms of $y$. 
are the same for both the transposed and untransposed transmission line, since the term containing the coefficient $K$ is very small.

The parameters in the $\alpha$-wave mode at $\mathrm{K}=7$ are equal to self parameters in the phase coordinates, as the velocity of wave propagation is the light velocity.

For large values of the self parameters in phase coordinates, the difference between the parmeters in the two wave modes $\alpha$ and $\beta$ will be zero. This difference also must be zero at $\mathrm{Z}_{\mathrm{bb}} \gg \mathrm{y}_{\beta}$. The difference between the parameters of both the completely transposed and the untransposed transmission lines becomes zero in the two wave modes $\alpha$ and $\beta$, while in the zero wave mode ${ }^{8}$ they will not be equal.

\section{THE BALANCE OF THE PARAMETERS FOR TRANSPOSED AND UNTRANSPOSED LINES}

Since the coefficient of unsymmetry $\mathrm{K}$ is varying for line inductance, the study of the parameter balancing is very important. A general form for the mutual parameters of the transposed line ${ }^{8}$ can be expressed as (Fig. 1e):

$\mathrm{Z}_{\mathrm{ab}}=\mathrm{Z}_{\mathrm{bc}}=\mathrm{Z}_{\mathrm{ac}}=2 \times 10^{-4} \ln \left(\frac{\mathrm{D}\left(\sqrt[6]{1}+3 \mathrm{~d}^{2} / \mathrm{D}^{2}\right)}{\mathrm{d}(\sqrt[3]{2})}\right) \mathrm{H} / \mathrm{Km}$

Using equation (5) the proposed coefficient of unsymmetry K may be approximately formulated as;

$\mathrm{K}=\frac{1}{1-\left(\frac{\ln 2}{\ln \mathrm{D} / \mathrm{d}}\right)}$

This coefficient of unsymmetry $\mathrm{K}$ for different values of the ratio $(\mathrm{D} / \mathrm{d})$ is computed as shown in Fig. 5. The large values of the ratio $(\mathrm{D} / \mathrm{d})$ means a small spacing between phases compared with the phase height above ground which can be considered as the case for the low voltage transmission line. In contrast, the small values of this ratio correspond to EHV and UHV overhead transmission lines. 


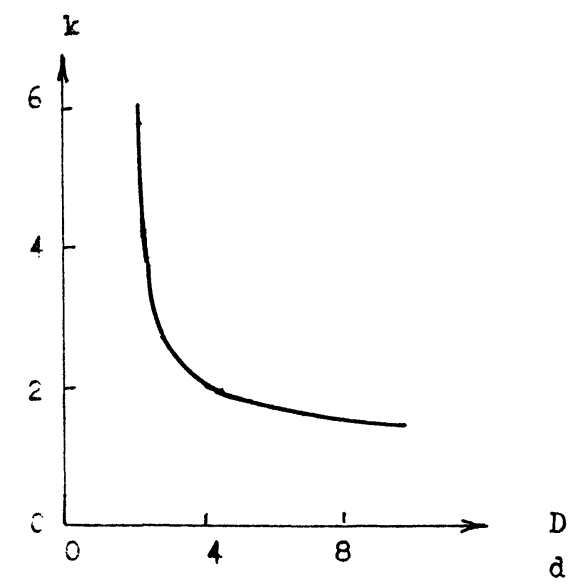

FIGURE 5 The coefficient of unsymmetry to distance ratio relation.

From Fig. 5, it is clear that the coefficient of unsymmetry $\mathrm{K}$ can be considered as the measurement for the line insulation level. Its value tends to infinity, theoretically, at $(\mathrm{D} / \mathrm{d})=2$. Also this coefficient $\mathrm{K}$ can be not more than 7 as concluded above.

\section{TRANSIENT CALCULATIONS IN TRANSPOSED AND UNTRANSPOSED LINES}

Previously the untransposed transmission lines were treated as transposed to simplify the problem of transient computations in these lines $^{11}$. This approach was suitable when the UHV and EHV transmission lines were not applied to the field of electric power networks.

Presently, long distance EHV and UHV have appeared in use and so they cannot be practically transposed. The coefficient of unsymmetry for such lines must be increased, and the assumption that the untransposed transmission lines are transposed with not be valied. The study of the difference between the value of the calculated voltage at any point $x$ on an untransposed line and that of its equivalent transposed is of interest.

The method of choice of transient computation is based on modal 
analysis $^{12}$, since it is suitable for both transposed and untransposed transmission lines.

The measurement of the difference between the two evaluated overvoltages in both transposed and untransposed lines is the major purpose of the study. Also the computed insulation level of the untransposed line may be deviated from the actual values if there is a large difference between the calculated values for both lines. This difference, $\Delta \mathrm{V}(\mathrm{x}, \mathrm{p})$ for single pole switching between the two computed voltages of the switched phase $V_{a}(x, p)$ at point $x$ of the untransposed line of length $\mathrm{L}$ and that of its equivalent transposed $V_{a}(x, p)$, when the sending voltage $E(p)$ is applied, can be derived in the final form as ${ }^{12}$ :

$$
\begin{aligned}
\Delta \mathrm{V}(\mathrm{x}, \mathrm{p})= & \mathrm{V}_{\mathrm{a}}(\mathrm{x}, \mathrm{p})-\grave{\mathrm{V}_{\mathrm{a}}}(\mathrm{x}, \mathrm{p}) \\
= & \frac{\mathrm{E}(\mathrm{p})}{2(\mathrm{~A}+\mathrm{B})}\left(\mathrm{A} \frac{\cosh \mathrm{s}_{\alpha}(\mathrm{L}-\mathrm{x})}{\cosh _{\alpha} \mathrm{L}}\right. \\
& -\frac{\mathrm{A}+\mathrm{B}}{3} \frac{\cosh \mathrm{s}_{\alpha}^{\prime}(\mathrm{L}-\mathrm{x})}{\cosh \mathrm{s}_{\alpha}^{\prime} \mathrm{L}}+2 \mathrm{~B} \frac{\cosh \mathrm{s}_{\beta}(\mathrm{L}-\mathrm{x})}{\cosh \mathrm{s}_{\beta} \mathrm{L}} \\
& -\frac{2}{3}(\mathrm{~A}+\mathrm{B}) \frac{\cosh \mathrm{s}_{\beta}(\mathrm{L}-\mathrm{x})}{\cosh \mathrm{s}_{\beta}^{\prime} \mathrm{L}}+\mathrm{A} \frac{\cosh \mathrm{s}_{\mathrm{o}}(\mathrm{L}-\mathrm{x})}{\cosh \mathrm{s}_{\mathrm{o}} \mathrm{L}} \\
& \left.-\frac{\mathrm{A}+\mathrm{B}}{3} \frac{\cosh \mathrm{s}_{\mathrm{o}}^{\prime}(\mathrm{L}-\mathrm{x})}{\cosh \mathrm{s}_{\mathrm{o}}^{\prime} \mathrm{L}}\right)
\end{aligned}
$$

where $\mathrm{A}$ and $\mathrm{B}$ are the coefficients of the transformation matrix of the transmission line parameters ${ }^{8}$. The propagation constants of the untransposed and transposed lines are $s_{\alpha, \beta, o}$ and $s_{\alpha, \beta, o}$ in the wave modes $(\alpha, \beta, 0)$, respectively and $\mathrm{P}$ is the Laplace operator.

From equation (7) it is seen that the calculated difference between the voltages of untransposed and transposed lines is a function of the line length $\mathrm{L}$, the distance $\mathrm{x}$ (at which the voltage must be estimated) and the time $t$.

As the $\beta$-wave mode is the same for the parameters of both transposed and untransposed transmission lines, equation (7) can be simplified as: 


$$
\begin{aligned}
\Delta \mathrm{V}(\mathrm{x}, \mathrm{p})= & \mathrm{V}_{\mathrm{a}}(\mathrm{x}, \mathrm{p})-\mathrm{V}_{\mathrm{a}}(\mathrm{x}, \mathrm{p}) \\
= & \frac{\mathrm{E}(\mathrm{p})}{2(\mathrm{~A}+\mathrm{B})}\left(\mathrm{A} \frac{\cosh \mathrm{s}_{\alpha}(\mathrm{L}-\mathrm{x})}{\cosh \mathrm{s}_{\alpha} \mathrm{L}}\right. \\
& -\frac{\mathrm{A}+\mathrm{B}}{3} \frac{\cosh \mathrm{s}_{\beta}(\mathrm{L}-\mathrm{x})}{\cosh \mathrm{s}_{\alpha}^{\prime} \mathrm{L}}+\frac{2}{3}(2 \mathrm{~B}-\mathrm{A}) \frac{\cosh \mathrm{s}_{\beta}^{\prime}(\mathrm{L}-\mathrm{x})}{\cosh \mathrm{s}_{\beta}^{\prime} \mathrm{L}} \\
& \left.+\mathrm{A} \frac{\cosh \mathrm{s}_{\mathrm{o}}(\mathrm{L}-\mathrm{x})}{\cosh _{\mathrm{o}} \mathrm{L}}-\frac{\mathrm{A}+\mathrm{B}}{3} \frac{\cosh \mathrm{s}_{\mathrm{o}}^{\prime}(\mathrm{L}-\mathrm{x})}{\cosh \mathrm{s}_{\mathrm{o}}^{\prime} \mathrm{L}}\right)
\end{aligned}
$$

Using equation (8) the percentage error in the evaluated voltage at any point $\mathrm{x}$ is computed. The results are tailored first with respect to frequency $(0,40,50,60 \mathrm{~Hz})$ for $500 \mathrm{kV}$ of lengths 500,800 and $1200 \mathrm{~km}$ as shown in Fig. 6 and second for a transmission line $500 \mathrm{~km}$, $500 \mathrm{kV}$ at $60 \mathrm{HZ}$ as a function of time as shown in Fig. 7.

The effect of the line length is also studied and the results of calculations are shown in Fig. 8 at zero, 40,50 and $60 \mathrm{~Hz}$ for different lengths.

From the above results it is concluded that the percentage error of the evaluated voltage greatly increases with the line length (Fig. 6 and

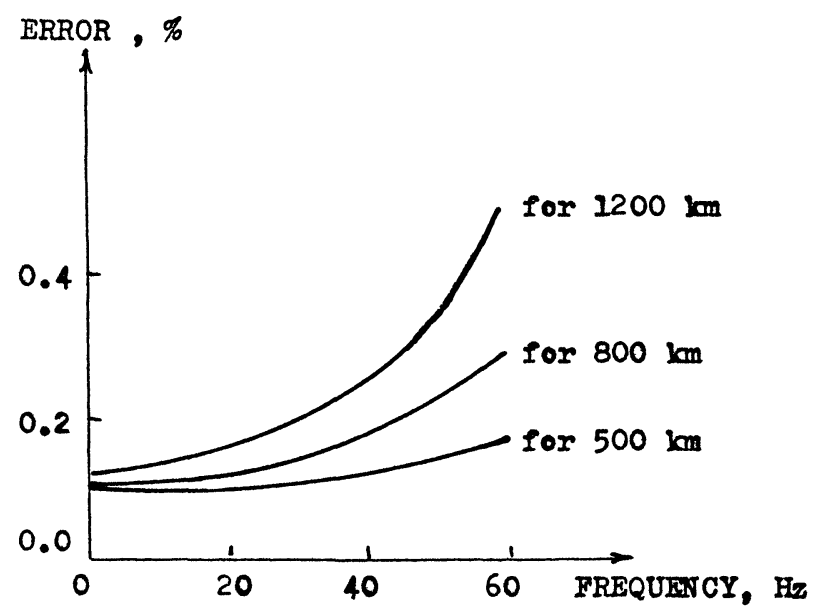

FIGURE 6 The calculated maximum percentage error in the receiving end voltage of a typical $500 \mathrm{kV}$ transmission line with different lengths as a function of frequency. 


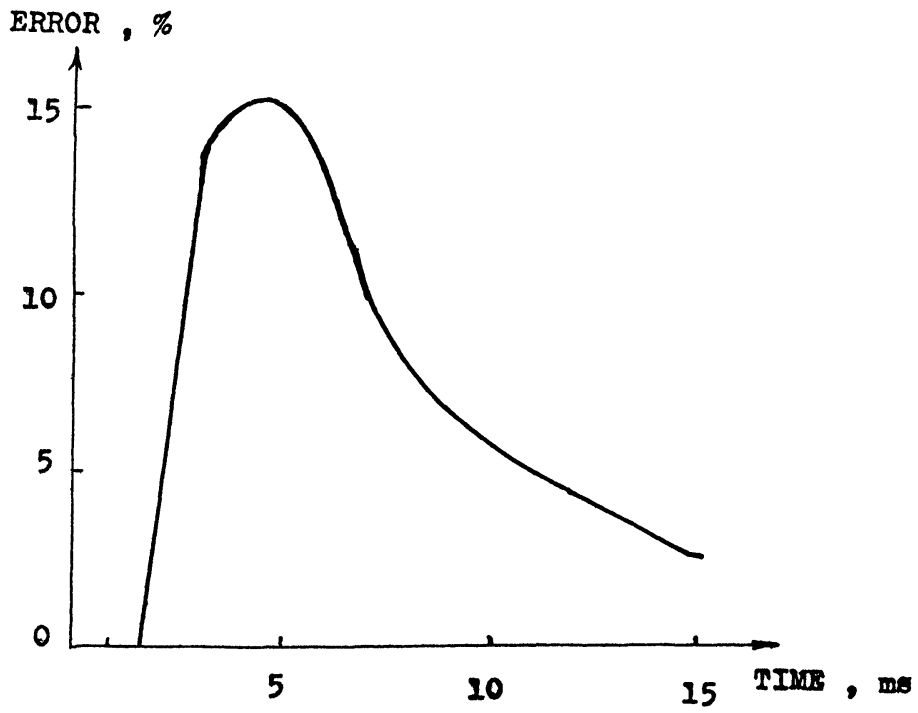

FIGURE 7 The determined percentage error in the voltage at receiving end of a $500 \mathrm{~km}, 500 \mathrm{kV}$ transmission line operating at $60 \mathrm{~Hz}$.

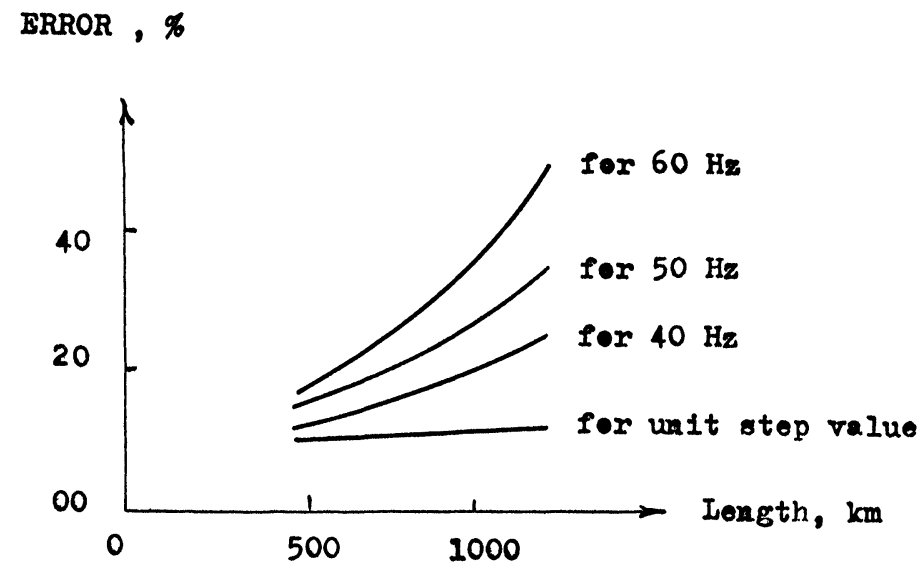

FIGURE 8 The calculated maximum percentage error in the value of terminal voltage for some lengths of a typical $500 \mathrm{kV}$ line. 
8) so that the long distance untransposed transmission line must be considered as untransposed. The calculations prove that the zero wave mode resistance of the line reduces the percentage error in the computed voltage. As this percentage error is a function of time, its value greatly decreases for steady state operations while it is maximum for transient duration (Fig. 7).

\section{CONCLUSIONS}

The maximum deviation in the values of the transmission line parameters in phase coordinates does not exceed $5.5 \%$ and the line may be suggested as horizontal type so that only one coefficient of unsymmetry can be proposed for long distance transmission line.

The parameters of the untransposed transmission line in the $\beta$-wave mode are the same as for transposed. The transmission line parameters in the $\alpha$-wave mode for large coefficients of unsymmetry equal to the phase parameters as the velocity of $\alpha$-wave propagation is the light velocity.

The percentage error in the computed voltage of an untransposed transmission line is a function of line length, the point at which the voltage should be evaluated, frequency and the time.

The long distance untransposed EHV and UHV must be not considered as transposed for transient calculations. These lines may be considered transposed only for steady state operations.

\section{ACKNOWLEDGEMENT}

The authors wish to express their thanks to Prof. Dr. A. Zietoun, Cairo University, for his valuable discussions in the present research.

\section{REFERENCES}

1. J.A. Rosales and F.L. Alvarado: Nonlinear frequency dependent transformer model for electromagnetic transient studies in power systems. IEEE Trans. vol. PAS-101, No. 11, (1982) 4281-4288.

2. J.R. Marti: Accurate modelling of frequency-dependent transmission line in electromagnetic transient simulations. IEEE Trans., vol. PAS-101, No. 1, (1982) 147-157. 
3. A.J. Eriksson, M.F. String Fellow and D.V. Meal: Lightning-induced overvoltages on overhead distribution lines. IEEE Trans., vol. PAS-101, No. 4 , (1982) 960-968.

4. H.W. Dommel: Digital computer solution of electromagnetic transients in single and multiphase networks. IEEE Trans., vol. PAS-88, (1969) 388-399.

5. M.M. Ahmed: Overvoltage analysis in new type transmission lines. Annual Scientific and Technological Issue of the Technical and Scientific Series, vol. 14, (1980) 52-66.

6. R.W. Long and D. Gelopulos: Component transformation-Eigen value analysis succinctly defienes their relationships. IEEE Trans., vol. PAS-101, No. 10 (1982) 4055-4063.

7. L. Thione: Overvoltages and insulation Co-ordination. General Report of Group 33, CIGRE, int. conf. for HV, Electra, No. 73, (1980) 134-142.

8. M. Hamed: On the possibility of transient calculations in single circuit untransposed transmission lines using Laplace transforms. J IEEEC, AmmanJordan, April 25-28, (1983) 39-43.

9. J.R. Carson: Wave propagation in overhead wires with ground return. Bell Syst. Teach. J., vol. 5, (1926) 539-554.

10. G.A. Korn and T.M. Korn: Mathematical Handbook For Scientists and Engineers. Book, McGraw-Hill Co., London, 1961.

11. J.P. Bickford et al: Computation of Power System Transients. Book, IEE Monograph Series No. 18, Peter Peregrinus Ltd., London, 1976.

12. M.M. Ahmed: Transient in transmission lines. Fifth inter. Congress for statistics, Computer science, social and demographic research, Cairo 29 March-3 April, vol. III, (1980) 83-95. 

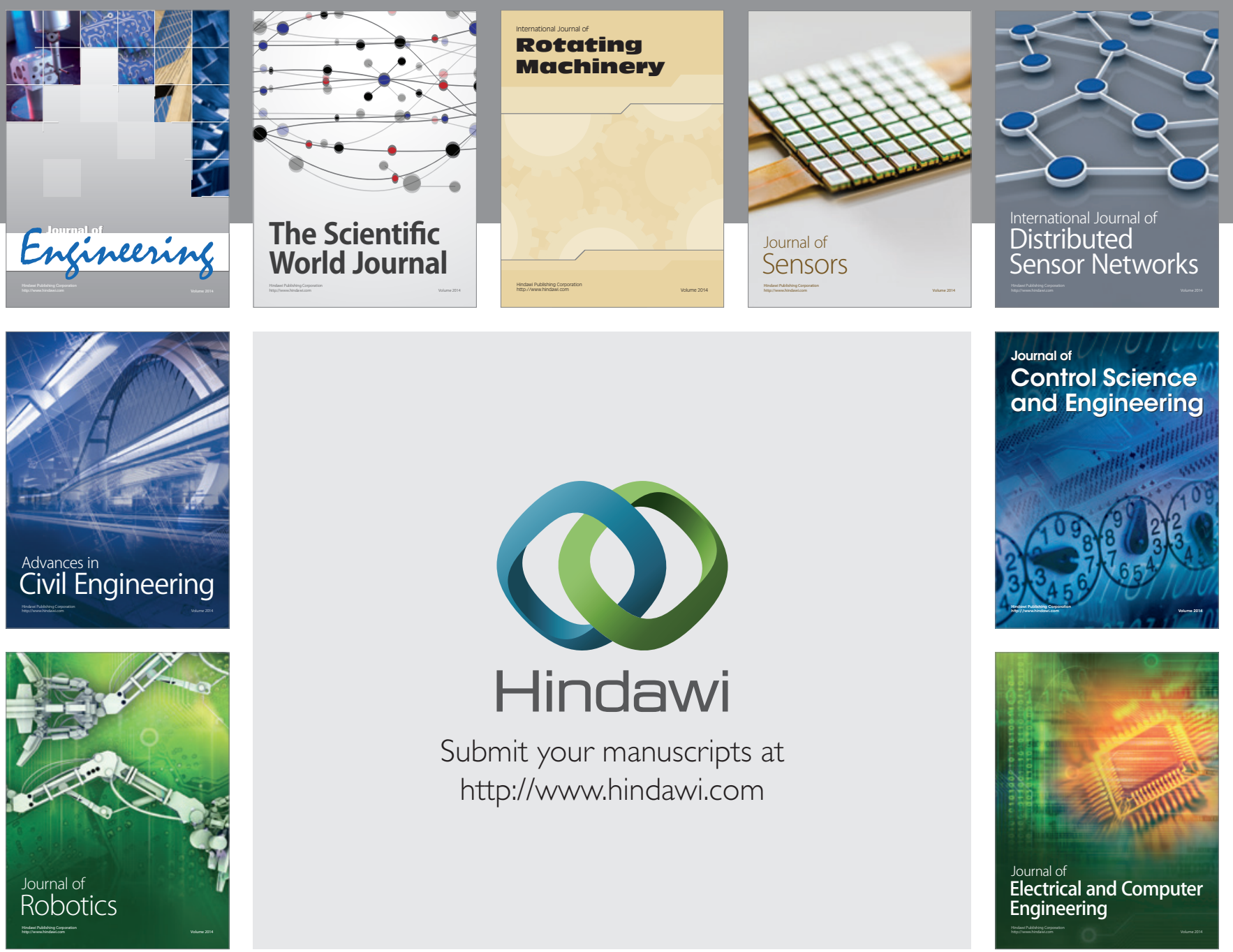

Submit your manuscripts at

http://www.hindawi.com
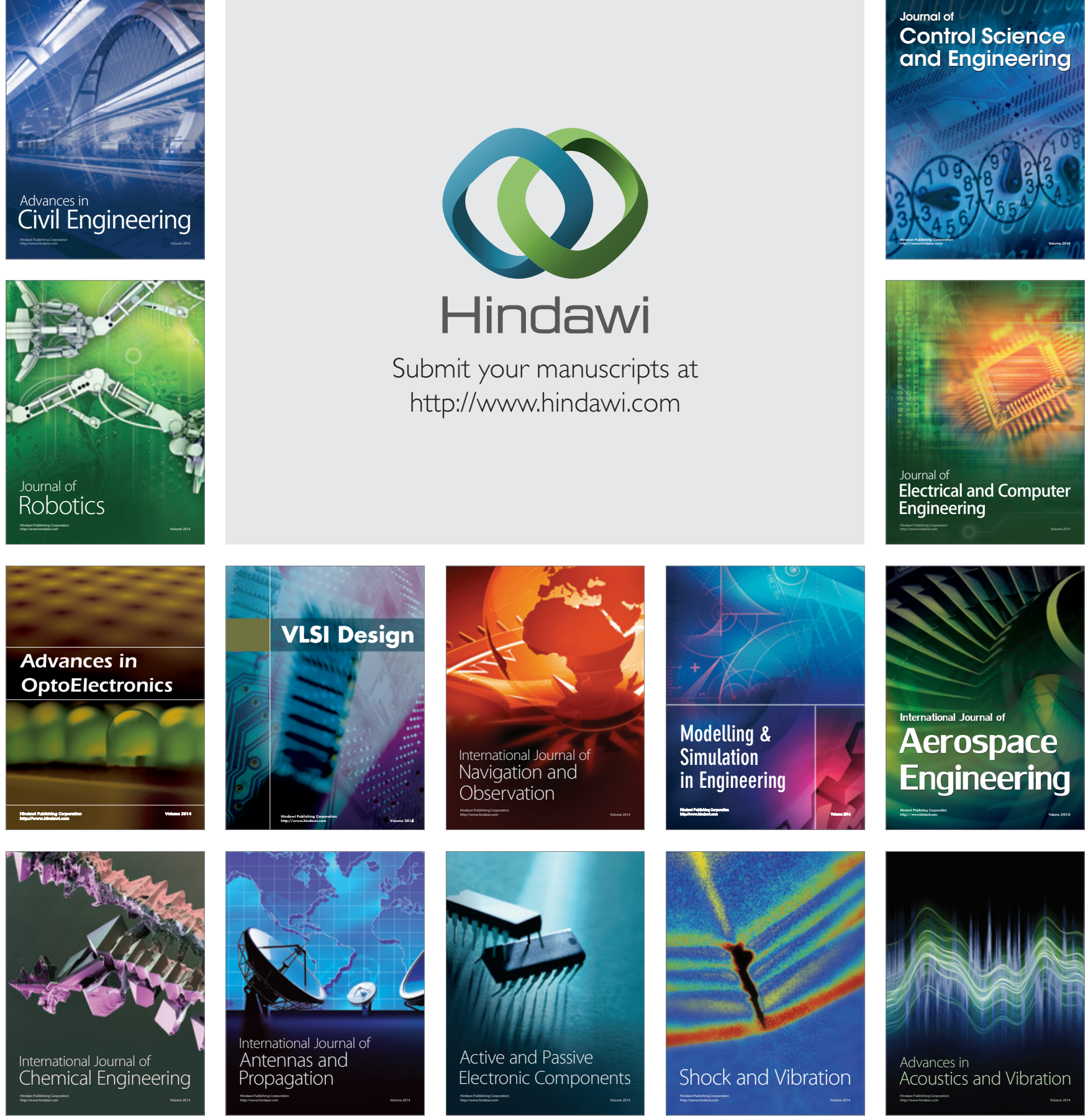